\title{
Prospects for Indigenous Australians in the Welfare System
}

\author{
Anne Daly
}

7 HE economic status of indigenous Australians has been the focus of considerable concern in recent government policy. ${ }^{1}$ Indigenous incomes at the individual level remain well below those of other Australians (see Figure 1) and over the period for which data exist there is only limited evidence that they are catching up.

This article provides an overview of the changes which have taken place in individual indigenous incomes and employment, and documents the importance of social security as a source of income for this group. Welfare transfers from government have played an important role in maintaining indigenous incomes. The article considers some of the issues raised by welfare dependence and its implications for the future economic status of indigenous Australians.

\section{Options for Raising the Incomes of Indigenous Australians}

A range of options exists for raising indigenous incomes. One possibility flows from the collective ownership of land by indigenous Australians, which has long been recognised. Beginning in the $1950 \mathrm{~s}$, mining royalties on indigenous land have been earmarked for indigenous people. The Aboriginal Land Rights (Northern Territory) Act 1976 gave indigenous Australians the right to claim unalienated Crown land and to receive compensation for mining activities in the Northern Territory. Most other States and Territories passed land rights legislation in the 1970s and 1980s which included mineral and royalty rights for indigenous Australians. A further important development was the High Court decision in the Mabo case in 1992, which recognised common law rights to land, based on traditional law and customs (Altman, 1994). These rights have been codified at the Commonwealth level in the Native Title Act 1993, subsequently amended in the Native Title Amendment Act 1998.

These collectively owned assets offer indigenous Australians the opportunity to develop sources of income growth for the community which will not be included in any individual calculations of income. Access to community infrastructure such as

\footnotetext{
'The term 'indigenous' is used throughout to refer to the Aboriginal and Torres Strait Islander populations of Australia.
}

Anne Daly is Senior Lecturer in Economics in the Faculty of Management at The University of Canberra. 
housing and vehicles is also important for some groups (Altman, 1996). However, these aspects of indigenous income are not discussed in this article, mainly because of a lack of reliable estimates as to their size. Consequently, the estimates of individual indigenous income presented here should be thought of as minimum estimates of their command over goods and services.

There are currently three other main options for generating income for indigenous Australians: mainstream employment, the Community Development Employment Projects (CDEP) scheme and social security payments. Mainstream employment offers the potential to generate rising incomes over time as the labour market skills of indigenous Australians improve. CDEP employment and welfare payments, while providing a minimum level of income, offer less potential for raising real income over time.

Indigenous Australians have not always had access to the safety net of government welfare payments. In the last 25 years, the social security system has changed the way it treats them. In the late 1970s, the Department of Social Security (DSS) increased its efforts to reach remote communities and to ensure that all who were eligible for welfare payments were receiving them. It was not until the carly $1980 \mathrm{~s}$ that people in remote communities became entitled to unemployment benefits (Altman \& Sanders, 1991). It is argued below that this incorporation of indigenous people into the welfare system has been a major reason for the rise in the individual incomes of indigenous females and has probably prevented individual indigenous male incomes from falling even further.

The safety net of social security payments is designed to provide a minimum standard of living. But it may also have the undesirable effect of reducing efforts to seek employment. The decision to search for work is related to the alternative income an individual can expect to receive from social security. Some individuals with limited labour markets skills and a large number of dependants can expect a lower income from work than from social security. While remaining on social security may be the best option for these individuals in the short run, it may limit their ability to develop labour market skills and reduce the possibility of gaining higher incomes in the long term.

An alternative to direct welfare payments (or 'sitdown money') for indigenous Australians is participation in the CDEP scheme. Under this scheme, indigenous communities can pool their unemployment benefit entitlements and, with the aid of additional government funds, work for their benefit entitlements on a part-time basis on community-based projects. The scheme has proved very popular and accounted for about a quarter of indigenous employment in 1994 (ABS/CAEPR 1996) and an estimated 23 per cent in 1996 (Taylor \& Bell, 1998).

\section{The Income and Employment Status of Indigenous Australians}

The major source of information on the economic status of indigenous Australians at a national level is the Population Census. In each census since 1971, people have been asked to identify themselves as Aboriginal or Torres Strait Islanders. This self-identification makes it difficult to interpret census results as reflecting changes 
over time, since each census snapshot relates to a different group of people. There is considerable evidence that people have become more willing to identify themselves as indigenous Australians over time, and this appears to have been particularly pronounced in the 1996 census (Choi \& Gray, 1985; Gray, 1997; Taylor, 1997; Hunter, 1998). In addition, the Australian Bureau of Statistics (ABS) has devoted considerable resources to improving the quality of the census data coming from remote areas (Taylor, 1992).

These caveats should be bome in mind in the following discussion of changes in income and employment over time. They are particularly important if the characteristics of the newly identified indigenous Australians differ systematically from those who had been so identified previously. While it is impossible to confirm directly, the indirect evidence suggests that the indigenous population identified in 1996, although 30 per cent larger than in 1991, is not markedly different from that identified in 1991 in terms of education levels, location of residence and age distribution (Gray, 1997; Taylor, 1997; Hunter, 1998).

A second source of aggregate information on the economic status of indigenous Australians is the National Aboriginal and Torres Strait Islander Survey (NATSIS) conducted by ABS in 1994 (ABS, 1995). This one-off survey covered 15,700 indigenous people and included questions on a range of issues not usually covered by ABS surveys. While the range of topics covered was extensive, the fact that no similar survey covering the non-indigenous population was conducted simultaneously means that it is not always easy to establish a comparison group for any results.

Figure 1

\section{Ratio of median indigenous to non-indigenous incomes for those aged 15-64 years, 1976-96}

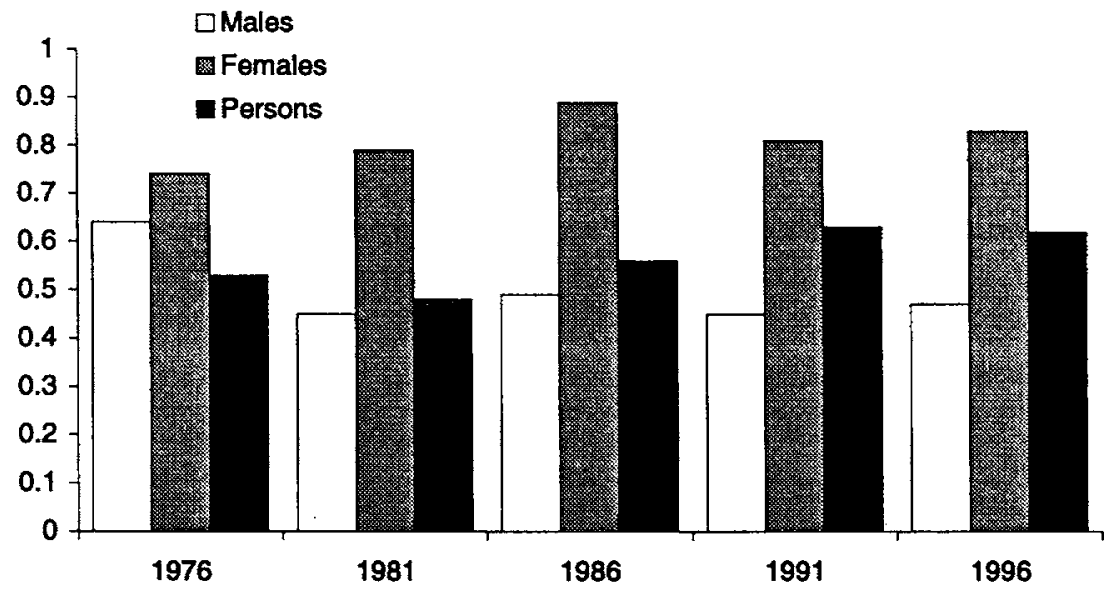

Sources: Daly (1995), ABS (1997). 
Figure 1 summarises the real median incomes of individual indigenous males and females compared with other Australians of working age between 1976 and 1996. The median income of indigenous adults as a group rose from 53 per cent of the median for other Australians in 1976 to 62 per cent in 1996. But this improvement masks quite different results for indigenous males and females. The median income for indigenous males aged 15-64 years actually fell relative to the median of other Australian males. In 1996, it stood at 47 per cent, compared with 64 per cent in 1976. In contrast, the indigenous female median income rose from 74 per cent of that of other Australian females to 83 per cent in 1996.

Much of the deterioration in the relative income of indigenous males can be explained by the falling proportion in employment. In 1976,56 per cent of the male indigenous population aged 15 years and over were in employment compared with 46 per cent in 1996. The latter figure includes CDEP participants working for their social security benefit entitlements. While the incomes of those not in employment were roughly the same for indigenous and non-indigenous males, the median income for employed indigenous males was lower than that of other Australian males in employment. This reflects partly the inclusion of CDEP participants among the employed, and partly the small proportion of indigenous males in well-paid occupations (see Daly, 1995, for further details).

CDEP employment and employment in community organisations have played important roles in maintaining indigenous employment at the recorded levels. Taylor and Bell (1998) estimate that only 26 per cent of the indigenous working age population was employed in mainstream jobs in 1996. Their calculations suggest that indigenous employment in mainstream jobs grew at 1.1 per cent a year in the intercensal period 1991-96, which was below the growth in the working-age population. There seems little basis for expecting mainstream employment growth in the medium term to change the income status of indigenous Australian males.

In contrast to the male experience of a declining employment/population ratio, indigenous females have experienced an increasing ratio, rising from 0.25 in 1976 to 0.33 in 1996 . While this probably contributed to rising individual incomes for indigenous females, the major explanation of the relative improvement in their incomes is the rise in the direct payment of welfare benefits. Indigenous females not in employment had a higher median income than other Australian females not in employment. After assessing the available evidence on relative changes in educational levels, age structure and family characteristics, Daly and Hawke (1995:36) conclude that for indigenous females 'changes in access to welfare payments and the incorporation of indigenous people from remote areas into the welfare system seems of fundamental importance in explaining the changes in their relative incomes'.

\section{The Extent of Welfare Dependence}

It is not possible to make an up-to-date comparison of the extent of welfare dependence among indigenous and other Australians based on census data. The last census which asked people about their sources of income was conducted in 1976. 
According to these data, indigenous Australians were more likely to be receiving social security payments than other Australians. Twenty four per cent of indigenous males were in receipt of such benefits, compared with 17 per cent of other Australian males and 33 per cent of indigenous females compared with 26 per cent of other Australian females (Daly \& Hawke, 1993).

Table 1 combines administrative data from the DSS and census data from 1991 to present a more up-to-date picture of the number of indigenous Australians receiving social security compared with all Australians of working age (Daly \& Hawke, 1994). In line with Commonwealth policy, the DSS now relies on indigenous people to self-identify. This choice, and the fact that the coding of information has not always been a priority with DSS officials, means that these figures are probably a minimum estimate of the numbers of indigenous people receiving social security. The extent of the under counting is considered to vary between areas and types of payment.

\section{Table 1}

Numbers of pensioners and beneficiaries per 100 people for indigenous and other Australians, by age, 1991

\begin{tabular}{lcccc}
\hline Age & \multicolumn{2}{c}{ Indigenous } & \multicolumn{2}{c}{ Total population } \\
& \% of recipients & Per $100^{2}$ & $\%$ of recipients & Per 100 \\
\hline $16-19$ & 10.6 & 13.8 & 5.5 & 16.3 \\
$20-29$ & 30.8 & 20.0 & 12.6 & 14.9 \\
$30-39$ & 24.8 & 22.3 & 11.2 & 13.3 \\
$40-49$ & 12.9 & 18.7 & 8.7 & 23.8 \\
$50-59$ & 10.7 & 26.3 & 10.6 & 22.1 \\
$60+$ & 10.2 & na & 51.4 & na \\
Total & 100.0 & & 100.0 & \\
\hline Total working age & & 20.0 & & 18.8 \\
\hline
\end{tabular}

Notes: "It has been necessary to compare DSS figures with population figures from the census to construct these ratios. Those identifying as Aboriginal and Torres Strait Islanders may differ between the two sources. ${ }^{b}$ Individuals aged $16-59$ years.

Source: Daly \& Hawke (1994).

According to these figures, 20 per cent of indigenous Australians of working age were receiving social security payments, compared with 19 per cent of the total population. This is not a big difference but it must be remembered that, in 1991, there were 18,000 indigenous participants in labour market programmes run by the Department of Employment, Education and Training (DEET) and there were 18,266 participants in the CDEP scheme run by the Aboriginal and Torres Strait Islander Commission (ATSIC). CDEP participants would be entitled to social security payments were they not in the scheme; and, when they are included in the total, the share of indigenous Australians of working age who were in receipt of public assistance doubled to 40 per cent, more than twice the rate of the Australian 
population in general. The addition of participants in DEET programs who were not already included as either DSS beneficiaries or CDEP participants would raise even further the share of those in receipt of government assistance. The figure of 40 per cent should be taken as indicative, as there may be some double counting between DSS and ATSIC figures; but there are also grounds, outlined above, for considering these figures as underestimates.

More recent figures from the NATSIS show that, in 1994, 63.4 per cent of the indigenous adult population reported government payments as their main source of income (ABS, 1995). These figures include those aged over 60 years, of whom a greater proportion might be expected to be reliant on welfare income. Birrell, Maher and Rapson (1997), using administrative data from the DSS and Department of Veterans Affairs, estimated that, in 1995, 32 per cent of all Australians aged 20 and over were primarily dependent on welfare payments. While these two estimates do not offer a perfect comparison, they suggest that dependence on welfare income is about twice as high in the indigenous community as among other Australians.

\section{Replacement Ratios}

This high level of welfare dependence raises another important question: what are the incentives for indigenous people to leave welfare? To answer this question fully, we would need to model the labour supply behaviour of indigenous Australians. Hunter and Daly (1998), using NATSIS data and DSS payment schedules, have taken a first step by estimating replacement ratios for indigenous Australians. The replacement ratio (the ratio of net income from welfare to net income from work) provides one summary measure of the incentives to work given the existence of an alternative income from the welfare system. The closer a replacement ratio is to one, the less incentive an individual has to work; and a replacement ratio greater than one means that the individual has no monetary incentive to work as he or she can receive a higher income from social security.

Table 2 presents estimates of replacement ratios for indigenous males and females according to their labour force status. Two alternative estimates of the expected wage from employment have been used. The first is based on the expected income for all indigenous males and females from all forms of non-CDEP employment, that is, full-time, part-time and seasonal work. The second calculation is based on an alternative employment income from full-time, full-year non-CDEP work. As the expected income from employment is higher under the second assumption, the replacement ratios are lower. However, since for many indigenous Australians part-time and seasonal work may be the most realistic employment options available, the first column may be more representative of the replacement ratios they face. 
Table 2

Replacement ratios across all labour force states, 1994

Basis of sample for wage estimation

$N$

(1)

(2)

All non-

Full-time,

CDEP workers ${ }^{a}$ full-year ${ }^{2}$

Single-adult income units

Single males

$\begin{array}{lrrrrr}\text { All } & 1791 & 0.69 & (0.27) & 0.54 & (0.15) \\ \text { CDEP } & 296 & 0.66 & (0.20) & 0.56 & (0.14) \\ \text { Unemployed } & 517 & 0.62 & (0.19) & 0.52 & (0.13) \\ \text { Non-CDEP } & 357 & 0.56 & (0.19) & 0.48 & (0.13) \\ \text { Not in labour force } & 621 & 0.85 & (0.32) & 0.59 & (0.16) \\ \text { Single females } & & & & & \\ \text { All } & 2161 & 0.81 & (0.24) & 0.58 & (0.13) \\ \text { CDEP } & 153 & 0.76 & (0.19) & 0.60 & (0.14) \\ \text { Unemployed } & 461 & 0.74 & (0.17) & 0.58 & (0.12) \\ \text { Non-CDEP } & 374 & 0.68 & (0.22) & 0.52 & (0.13) \\ \text { Not in labour force } & 1173 & 0.89 & (0.25) & 0.60 & (0.13)\end{array}$

Married/de facto married income units

If female partner is dependent (i.e. indigenous male partner looking for work)

$\begin{array}{lrrrrr}\text { All } & 1939 & 0.91 & (0.23) & 0.81 & (0.17) \\ \text { CDEP } & 380 & 1.00 & (0.24) & 0.89 & (0.18) \\ \text { Unemployed } & 485 & 0.92 & (0.21) & 0.82 & (0.16) \\ \text { Non-CDEP } & 727 & 0.85 & (0.20) & 0.77 & (0.16) \\ \text { Not in labour force } & 347 & 0.92 & (0.25) & 0.80 & (0.17)\end{array}$

If male partner is dependent (i.e. indigenous female partner looking for work)

All

CDEP

Unemployed

Non-CDEP

Not in labour force
2216

221

300

504

1191
$1.22(0.29)$

$1.31 \quad(0.31)$

$1.18(0.24)$

1.10

1.27

$(0.26)$

$(0.30)$

$0.89(0.18)$

$0.98 \quad(0.21)$

$0.90 \quad(0.16)$

$0.83(0.16)$

$0.89 \quad(0.18)$

Notes: Replacement ratios for married income units are calculated by dividing the social security entitlement of both partners by the expected net income from non-CDEP wages (and consequent family payment entitlements when employed) of the partner looking for work. Other family income is held constant throughout.

'Standard deviations are in brackets.

Source: Hunter and Daly (1998).

The replacement ratios are presented separately for single males and females and for males and females who were members of a married or de facto married relationship. The average replacement ratio for virtually all the groups identified here is over 0.50; that is, the average indigenous Australian could expect to receive 
at least half of their expected income from employment from social security benefits. More specifically, by way of example, the table shows that the average single indigenous male could expect to receive 69 per cent of the average employment income for this group from welfare payments.

The table shows that the average replacement ratio for single males and females is highest for those not in the labour force but does not differ substantially between those in CDEP employment or unemployment. As might be expected, the lowest replacement ratios were for those already in non-CDEP employment. The ranking across labour market states was, however, less clear for those who were married or in a de facto marriage relationship. While those in non-CDEP employment faced the lowest replacement ratios for each comparison group, the ranking differed for the other three labour force status groups.

Two other important features of the table are worth noting. The replacement ratios were higher for females than males, and higher for those who were married or in a de facto marriage relationship. The first result reflects the lower earnings of females compared with males; the second, the fact that the welfare system explicitly recognised the additional costs of supporting a dependent spouse while employers do not. The replacement ratios in excess of one for partnered women in all labour force categories compared with all non-CDEP employment show that for these women, their expected income was higher from welfare payments than from employment.

The results presented in this table are averages, which may differ substantially from the replacement ratios facing particular individuals. More detailed calculations presented in Hunter and Daly (1998) show that, among single males and females, about 20 per cent of individuals could expect a higher income from welfare than from employment in non-CDEP work. Among those in partnered relationships, the share was higher: 30 per cent for males with a dependent partner and looking for work, and almost 80 per cent for females with a dependent partner and looking for work.

Evidence from earlier Australian studies and the international literature suggest that the replacement ratio influences duration of employment (Committee on Employment Opportunities, 1993; Jackman, 1998). It is therefore perhaps not surprising, given the relatively high replacement ratios for the unemployed and those on CDEP, that indigenous Australians have relatively long unemployment durations (ABS/CAEPR, 1996).

\section{The CDEP Scheme}

While linked to the welfare system, the CDEP scheme offers indigenous Australians the possibility of developing labour market skills and establishing indigenous enterprises which may in the long term be profitable. Each CDEP community is unique, with outcomes ranging from the development of successful businesses operating in the wider community to examples where the scheme merely provides a vehicle for transferring social security payments to individuals with little in the way of a real work requirement (Deloitte Touche Tohmatsu, 1993; Smith, 1994, 1995, 
1996). Employment activities which have been undertaken under the CDEP scheme include clothing manufacture, market gardening, emu farming, firewood collection, maintenance of sacred sites, cultural education for children, rubbish removal and housing repairs (Smith, 1995). Some of these activities have the potential to become self-supporting. While there are examples of this, they are few in number.

An important aspect of the scheme is its 'indigenousness'. In a familiar environment, it is possible that indigenous people are more likely to develop skills which would remain untapped in mainstream employment. For many, the opportunity of working in an indigenous environment is invaluable and compensates for the low incomes relative to those available from mainstream jobs.

However, there is limited evidence of individuals moving off CDEP into mainstream employment (Taylor \& Altman, 1997). There is also a danger that, as work is part-time and payments are limited to social security benefits, the opportunities and incentives to develop labour market skills are reduced. This point may be particularly important for young people deciding whether to continue schooling. If CDEP employment is the most likely outcome for these young people, it offers little incentive to stay at school past the compulsory years.

\section{Summary and Conclusions}

This article has documented the relative individual income status of indigenous Australians and the extent of their welfare dependence. The available evidence shows a deterioration in relative indigenous male incomes between 1976 and 1991, offset by the rise in the relative incomes of indigenous females. The former can be attributed mainly to the reduction in the proportion of indigenous males in employment, and the latter to the increased access to welfare payments for indigenous females. The estimates presented here show that, in 1991, about 40 per cent of working age indigenous Australians received social security benefits (including the CDEP scheme), about double the rate among other Australians. Other estimates support this conclusion. Without the safety net of the welfare system, the current plight of indigenous Australians could well be much worse.

However, a longer-term view of the current situation raises major concerns. Those on social security payments may find themselves in poverty traps with little incentive to find work. CDEP scheme participants may also face a future of low income. Unless activities undertaken under the CDEP scheme can successfully generate income for indigenous communities or provide a vehicle for expanding labour market experience for indigenous people who then move into mainstream jobs, participants on the scheme will continue to be working for their social security entitlements. There is limited evidence to date that the CDEP scheme has achieved these goals, though it may do so in the long term.

\footnotetext{
${ }^{2}$ Case studies of successful schemes in Port Lincoln, Newcastle and Redfern have been documented by Smith $(1994,1995,1996)$.
} 


\section{Anne Daly}

For many of those on welfare, the replacement ratios presented above suggest that there is little financial incentive to search for mainstream employment. There is a real danger of poverty traps for indigenous Australians. A feature of the welfare system is that, as the number of dependants increases, so does the size of the welfare payment. This creates high replacement ratios for this group of people with relatively little in the way of labour market skills and high fertility rates. The incentives to search for work and perhaps break the cycle of welfare dependence is limited. Those living in remote areas face the additional costs associated with migration to areas with employment opportunities.

The replacement ratio can be altered by either reducing welfare payments or raising potential employment income. The former strategy would impose substantial short-term costs on indigenous Australians. The latter requires that indigenous Australians gain more labour market skills and that barriers to employment, such as racial discrimination, are reduced. These are major long-term goals for policy makers. 


\section{References}

Altman, J. (1994), 'Economic Implications of Native Title: Dead End or Way Forward?', pp. 61-78 in W. Sanders (ed.), Mabo and Native Title: Origins and Institutional Implications, Australian National University, Canberra (CAFPR Research Monograph No. 7).

(1996), 'Aboriginal Economic Development and Land Rights in the Northern Territory: Past Performance, Current Issues and Strategic Options', Centre for Aboriginal Economic Policy Research, Australian National University, Canberra (CAEPR Discussion Paper No. 126).

— \& W. Sanders (1991), 'From Exclusion to Dependence: Aborigines and the Welfare State in Australia', Centre for Aboriginal Fconomic Policy Research, Australian National University, Canberra (CAEPR Discussion Paper No. 1).

Australian Bureau of Statistics (ABS) (1995), National Aboriginal and Torres Strait Islander Survey 1994: Detailed Findings, Canberra (Cat. No. 4190.0).

- (1997), Indigenous Thematic Profile: 1996 Census of Population and Housing, Canberra (Cat. No. 2020.0).

Australian Bureau of Statistics \& Centre for Aboriginal Economic Policy Research (ABS/CAEPR) (1996), Employment Outcomes for Indigenous Australians, Canberra (Cat. No. 4199.0).

Birrell, B., C. Maher \& V. Rapson (1997), 'Welfare Dependence in Australia', People and Place 5(2): 68-77.

Choi C. \& A. Gray (1985), An Evaluation of Census Counts of the Aboriginal Population, 1971, 1976 and 1981 Censuses, ABS, Canberra (Occasional Paper No. 1985/2).

Committec on Employment Opportunities (1993), Restoring Full Employment: A Discussion Paper, AGPS, Canberra.

Daly, A. (1995), Aboriginal and Torres Strait Islander People in the Labour Market, 1986 and 1991, ABS, Canberra (Cat. No. 6253.0).

Daly, A. \& A. Hawke (1993), 'Work and Welfare for Indigenous Australians', Centre for Aboriginal Economic Policy Research, Australian National University, Canberra (CAEPR Discussion Paper No. 48).

(1994), 'How Important is the Welfare System as a Source of Income for Indigenous Australians?', Economic Papers 13(3): 74-83.

(1995), The Impact of the Welfare State on the Economic Status of Indigenous Australian Women', The Australian Economic Review (4th Quarter): 29-42.

Daly, A. \& D. Smith (1998), 'Indigenous Sole Parent Families: Welfare Dependency and Work Opportunities', Australian Bulletin of Labour 24(1): 47-66.

Deloitte Touche Tohmatsu (1993), 'No Reverse Gear: A National Review of the Community Development Employment Projects Scheme', Canberra (a report to ATSIC).

Gray, A. (1997), 'The Explosion of Aboriginality: Components of Indigenous Population Growth 1991-96', Centre for Aboriginal Economic Policy Research, Australian National University, Canberra (CAEPR Discussion Paper No. 142). 
Hunter, B. (1998), 'Assessing the Utility of 1996 Census Data on Indigenous Australians', Centre for Aboriginal Economic Policy Research, Australian National University, Canberra (CAFPR Discussion Paper No. 154).

—_ A. Daly (1998), 'Labour Market Incentives Among Indigenous Australians: The Cost of Job Loss versus the Gains from Employment', Centre for Aboriginal Economic Policy Research, Australian National University, Canberra (CAEPR Discussion Paper No. 159).

Jackman, R. (1998), 'European Unemployment: Why Is It so High and What Should be Done About it?', paper delivered at an RBA/CEPR conference on unemployment, Sydney (June).

Smith, D. (1994), "Working for CDEP": A Case Study of the Community Development Employment Projects Scheme in Port Lincoln, South Australia', Centre for Aboriginal Economic Policy Research, Australian National University, Canberra (CAEPR Discussion Paper No. 75).

- (1995), 'Redfern Works: The Policy and Community Challenges of an Urban CDEP Scheme', Centre for Aboriginal Economic Policy Research, Australian National University, Canberra (CAEPR Discussion Paper No. 99).

- (1996), 'CDEP as Urban Enterprise: The Case of Yarnteen Aboriginal and Torres Strait Islanders Corporation, Newcastle', Centre for Aboriginal Economic Policy Research, Australian National University, Canberra (CAEPR Discussion Paper No. 114).

Taylor, J. (1992), 'Aboriginal Population Change in Remote Australia 1986-91: Data Issues', Centre for Aboriginal Economic Policy Research, Australian National University, Canberra (CAEPR Discussion Paper No. 34).

- (1997), 'Changing Numbers, Changing Needs? A Preliminary Assessment of Indigenous Population Growth 1991-96', Centre for Aboriginal Economic Policy Research, Australian National University, Canberra (CAEPR Discussion Paper No. 143).

Taylor, J. \& J. Altman (1997), The Job Ahead: Escalating Economic Costs of Indigenous Employment Disparity, ATSIC, Canberra.

Taylor, J. \& M. Bell (1998), 'Estimating Intercensal Indigenous Employment Change, 1991-96', Centre for Aboriginal Economic Policy Research, Australian National University, Canberra (CAEPR Discussion Paper No. 155).

I would like to thank Jon Altman, Anne Hawke, Boyd Hunter, Diane Smith and John Taylor for their valuable assistance and collaboration over the years. An earlier draft of this article was presented at a seminar at Queensland University of Technology and has benefited from the comments of the participants. Any remaining errors are, of course, my responsibility. 